\title{
Satisfaction with Therapy Among Patients with Chronic Noncancer Pain with Opioid-Induced Constipation
}

\author{
Robert J. LoCasale, PhD, MS; Catherine Datto, MD, MS; \\ Mary Kay Margolis, MHA, MPH; and Karin S. Coyne, PhD, MPH
}

\begin{abstract}
BACKGROUND: Greater satisfaction with medication is associated with better adherence; however, specific to opioid-induced constipation (OIC), data on the relationship between medication satisfaction and efficacy are lacking.
\end{abstract}

OBJECTIVE: To understand satisfaction with therapy among patients with chronic noncancer pain and OIC.

METHODS: A prospective longitudinal study was conducted in the United States, Canada, Germany, and the United Kingdom using web-based patient surveys. Patients on daily opioid therapy for $\geq 74$ weeks for the treatment of chronic noncancer pain with OIC were recruited from physician offices and completed a web-based survey at baseline and weeks 2, 4, 6, 8, 12, 16, 20, and 24. When completing each survey, patients selected the remedies used in the previous 2 weeks to relieve constipation; options included natural/ behavioral therapies, over-the-counter (OTC) therapies, and prescription laxatives. Patients selected the amount of relief and satisfaction with each selected therapy. Descriptive statistics were calculated; Spearman's correlations were calculated for symptom relief and satisfaction.

RESULTS: Mean age of the 489 patients who met the criteria for OIC and completed the baseline survey was $52.6 \pm 11.6$ years; $62 \%$ were female; $85 \%$ were white. Increasing levels of relief from constipation were associated with increasing levels of satisfaction for all agents; correlations were $>0.55$ and statistically significant $(P<0.001)$. Among the patients who had used OTC therapies in the 2 weeks prior to baseline, $54 \%$ to $73 \%$ reported that they were somewhat or very satisfied with the therapy. Yet, of these satisfied patients, $28 \%$ to $63 \%$ experienced no or only slight relief from the therapy. Twenty percent to $79 \%$ of the patients who had used prescription laxatives in the 2 weeks prior to baseline reported being at least somewhat satisfied with the therapy.

CONCLUSIONS: These results indicate that there is a high rate of inadequate response to laxatives for patients with OIC that persisted for the 6 months of this study. While increased relief from constipation was associated with increased satisfaction for all therapies, there remains a substantial number of patients who report satisfaction despite having only inadequate relief from OIC that merits further investigation.

J Manag Care Spec Pharm. 2016;22(3):246-53

Copyright $\odot 2016$, Academy of Managed Care Pharmacy. All rights reserved.

\section{What is already known about this subject}

Opioid-induced constipation (OIC) is a common condition, with a prevalence of $40 \%$ to $64 \%$ in patients with noncancer pain, which can impair patients' abilities to carry out activities of daily living and is associated with lower overall health and well-being.
Available laxative therapies for OIC leave the patient with significant residual symptoms. Understanding patient satisfaction and perceived relief with the products could be informative to OIC management, as the symptom burden of OIC is significant, bothersome, and persistent.

\section{What this study adds}

These analyses were conducted to generate real-world empirical evidence to better understand the ways in which patients with chronic noncancer pain and OIC try to address their constipation symptoms and the effectiveness of and satisfaction with these constipation treatments.

High proportions of the patients in this study received no relief at all or only slight relief with each of the therapies, but yet were still satisfied and willing to continue with the therapy.

In light of available therapies, when patients and their prescribers did have a discussion about OIC, the most common recommendation by the prescribers was to take an opioid holiday.

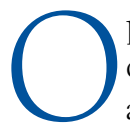
pioid-induced constipation (OIC) is the result of mu opioid receptor activation in the gastrointestinal tract among individuals treated with opioid analgesics. ${ }^{1}$ OIC is a common condition, with a prevalence of $40 \%$ to $64 \%$ in patients with noncancer pain..$^{2-5}$ OIC-related symptoms impair patients' abilities to carry out activities of daily living, result in work time missed and diminished work productivity, and are associated with lower overall health and well-being.,6-8 The management of OIC encompasses both nonpharmacologic and pharmacologic approaches, ${ }^{1}$ with laxatives being the usual treatment for OIC symptoms. ${ }^{9}$

Available laxative therapies address one component of physiologic mechanisms underlying constipation, while the mechanism of OIC is driven by a combination of mechanisms including decreased gut motility, decreased gut secretions, and improper function of the anal sphincter. Targeting the underlying cause of the OIC, those functions driven by mu receptor function in the gut, may provide greater relief. Available laxative therapies for OIC leave the patient with significant residual symptoms. ${ }^{10}$ Understanding patient satisfaction and perceived relief with products could be informative to OIC management. 
Assessing satisfaction with medication evolved from the emerging interest in patient satisfaction with medical care in the early to mid-1990s, ${ }^{11}$ a reflection of the rise of the patient as an active consumer rather than merely as a passive recipient. ${ }^{12}$ Greater satisfaction with medication is associated with better adherence and improved persistence, ${ }^{13}$ which has been demonstrated in multiple disease areas, including rheumatoid arthritis, ${ }^{14}$ osteoporosis, ${ }^{15}$ and erectile dysfunction. ${ }^{16}$ However, research specific to OIC and the relationship of medication satisfaction and efficacy or satisfaction and persistence are lacking.

Therefore, the objective of this analysis was to understand satisfaction and perceived relief or benefit of laxatives (overthe-counter [OTC] and prescription) and behavioral/natural therapies over time among adults with OIC.

\section{Methods}

\section{Study Design}

Details regarding the study design, patient recruitment, and data collection have been previously described but are summarized here. ${ }^{7}$ This prospective longitudinal study was conducted in the United States, Canada, Germany, and United Kingdom to assess the burden of OIC in patients with noncancer pain using a combination of patient surveys, medical record data abstraction, and physician surveys. Since the purpose of this analysis was to describe patient satisfaction and perceived relief or benefit of OIC, only the overall patient survey and physician survey data is presented and discussed; no country-specific data are presented.

The study received institutional review board approval prior to initiation, and patients provided informed consent to participate. The patient-reported component of the study included an internet-based survey at baseline and 8 follow-up surveys over 24 weeks (weeks 2, 4, 6, 8, 12, 16, 20, and 24). Physicians completed a survey at baseline and at week 24 about the experience of individual patients who completed the baseline survey.

\section{Study Sample and Data Collection}

The study sample was composed of patients recruited from primary care clinics, pain management clinics, and clinical research sites affiliated with primary care networks. Patients were required to have documentation of daily opioid therapy lasting for $\geq 4$ weeks for the treatment of chronic noncancer pain in their clinical charts and also to report OIC during their screening interview. Staff at the clinical site reviewed their site's medical charts or database to identify a preliminary cohort of potentially eligible patients. Staff then described the study and the informed consent process to each identified patient. Interested patients were provided with a welcome email/ letter with instructions for logging in to the survey website. Participants were compensated for their time in the form of an electronic gift card in the country's currency, with values ranging from the equivalent of U.S. $\$ 15$ to $\$ 25$.
Patient Survey. The patient survey included questions from standardized questionnaires and questions developed for this study. The key data collected for these analyses are described here. During each survey time point, patients completed items about their opioid pain medication usage. In particular, they indicated changes in opioid use to address their bowel symptoms: "In the past 7 days, did you change how you used your opioid pain medications so that you could have a bowel movement (BM)?" If the patient indicated a change in opioid use in some way, he/she then indicated (yes/no) whether he/ she was satisfied with how the change relieved constipation.

During each survey time point, patients selected the laxative remedies they had used to relieve their constipation in the previous 2 weeks. Options included natural therapies (probiotics, increased fluids, increased exercise, natural diet change), OTC therapies (fiber supplements, stool softeners, laxatives), and prescription laxatives. Follow-up questions to each therapy included the amount of relief and satisfaction with the treatment:

- To assess the amount of relief, patients were asked, "How well did <product> relieve your constipation?" and responded via 4 response options: "No relief," "Slight relief," "Moderate relief," and "Complete relief."

- To assess satisfaction with the treatment, patients were asked, "How satisfied were you with < product> for your constipation?" Possible responses were "Very satisfied," "Somewhat satisfied," "Somewhat dissatisfied," and "Very dissatisfied." Satisfied patients were asked to specify the reason(s) that they were satisfied with the constipation treatment. Responses included "Relief of constipation," "Convenient to take or use," "No or few side effects," "Inexpensive," and "Other." Dissatisfied patients were asked to specify the reason(s) they were dissatisfied with the treatment, selecting from the following responses: "Did not relieve constipation," "Stools too loose," "Feeling of needing to have a BM comes on too quickly, almost had accidents," "Could not tolerate side effects of treatment," "Inconvenient to take or use (for example, have to take it too often)," "Unpleasant to take or use (for example, bad taste)," "Expensive," and "Other."

To further assess overall satisfaction, patients completed the global assessment of treatment benefit, satisfaction, and willingness to continue (BSW) instrument. ${ }^{17}$ The perception of treatment benefit question asks patients if they perceived a benefit from treatment. If yes, the patient was then asked if the perceived benefit was of little or much benefit. The satisfaction question asked patients if they were satisfied with treatment. If yes, the patient was then asked if he/she was a little satisfied or very satisfied. If no, the patient was asked if he/she was a little dissatisfied or very dissatisfied. The willingness to continue question asked patients if they were willing to continue with treatment. If yes, the patient was then asked if he/she was a little bit willing or very willing. If no, the patient was asked if he/she was a little unwilling or very unwilling. 
Physician Survey. The physician survey consisted of questions designed to capture the perceived burden of illness of OIC, symptoms, treatment patterns for OIC, laxative use, and patients' overall OIC treatment satisfaction. Physicians completed items on treatment recommendations for OIC and opioid pain medication. The baseline physician survey also included a yes/no item if the physician thought that the patient was experiencing constipation.

\section{Statistical Analysis}

All analyses were performed using SAS version 9.4 (SAS Institute, Cary, NC) following a statistical analysis plan approved prior to receipt of the locked and clean dataset. The data were analyzed as observed, without imputation for missing responses. Descriptive statistics were used to evaluate outcomes at baseline and at each of the follow-up study visits. For continuous variables, the mean and standard deviation (SD) were described; for categorical variables, the number and percent distribution by category were described. Spearman's correlations were calculated for symptom relief and satisfaction. The correlations are inversely related due to response patterns in item wording.

\section{Results}

Of 500 recruited patients, 489 (97.8\%) met the criteria for OIC and completed the baseline survey.

\section{Demographic and Clinical Characteristics}

The mean age of patients was $52.6 \pm 11.6$ years (median $=54.0$; Table 1). The majority (62\%) of patients were female and $85 \%$ were white. Almost two thirds (62\%) rated their overall health as fair or poor. Overall, back pain (77\%) and joint pain (52\%) were the most common types of chronic pain experienced by patients. Patients had a mean $( \pm S D)$ of $9.8 \pm 8.9$ years with chronic pain (median $=7.0$ ) and had used opioid medication for a mean $( \pm S D)$ of $6.4 \pm 6.3$ years (median $=4.2)$. Almost half of patients (49\%) reported that constipation moderately or completely interfered with the ability of their opioid medication to control their pain.

\section{Patient-Reported Relief and Satisfaction with Constipation Therapies over Time}

The highest proportions of patients used natural/behavioral therapies over the 6-month follow-up period (27\%-72\%). The most common OTC strategy was stimulant laxatives $(n=146$, $30 \%$ ) and the least common was rectal options ( $n=36,7 \%)$. For prescription products, osmotic laxatives had the most users $(\mathrm{n}=48,10 \%)$, and Relistor $(\mathrm{n}=2,<1 \%)$ had the fewest users. (Relistor was not approved in the United Kingdom, Canada, or Germany for patients with noncancer pain and was only approved in the United States in September 2014, after this study was completed.)
TABLE 1 Patient-Reported Baseline Demographics and Clinical Characteristics

\begin{tabular}{|c|c|c|}
\hline \multirow[b]{2}{*}{ Sex, female, n (\%) } & \multicolumn{2}{|c|}{$\begin{array}{l}\text { Overall } \\
(\mathrm{N}=489)\end{array}$} \\
\hline & 304 & $(62.2)$ \\
\hline Age (mean \pm SD years) & 52.6 & \pm 11.6 \\
\hline \multicolumn{3}{|l|}{ Race, n (\%) } \\
\hline White/Caucasian & 415 & $(84.9)$ \\
\hline Black & 24 & $(4.9)$ \\
\hline Asian & 22 & $(4.5)$ \\
\hline Hispanic/Latino/Latin American & 9 & $(1.8)$ \\
\hline Other or prefer not to state & 18 & $(3.7)$ \\
\hline Missing & 1 & $(0.2)$ \\
\hline \multicolumn{3}{|l|}{ Health rating, n (\%) } \\
\hline Excellent & 7 & $(1.4)$ \\
\hline Very good & 33 & $(6.7)$ \\
\hline Good & 145 & $(29.7)$ \\
\hline Fair & 207 & $(42.3)$ \\
\hline Poor & 94 & $(19.2)$ \\
\hline Missing & 3 & $(0.6)$ \\
\hline \multicolumn{3}{|l|}{ Type of chronic pain, ${ }^{\mathrm{a}} \mathrm{n}(\%)$} \\
\hline Back pain & 375 & $(76.7)$ \\
\hline Joint pain & 252 & $(51.5)$ \\
\hline Pain syndrome & 162 & $(33.1)$ \\
\hline Neuralgia & 115 & $(23.5)$ \\
\hline Osteoarthritis & 95 & $(19.4)$ \\
\hline Headache or migraine & 78 & $(16.0)$ \\
\hline Fibromyalgia & 71 & $(14.5)$ \\
\hline Rheumatoid arthritis & 41 & $(8.4)$ \\
\hline Other & 76 & $(15.5)$ \\
\hline Duration of chronic pain (mean \pm SD years) & \multicolumn{2}{|c|}{$9.8 \pm 8.9$} \\
\hline Duration of opioid medication use (mean \pm SD years) & \multicolumn{2}{|c|}{$6.4 \pm 6.3$} \\
\hline $\begin{array}{l}\text { How much does constipation interfere with the } \\
\text { ability of your opioid medication to control pain? n (\%) }\end{array}$ & \multicolumn{2}{|c|}{$\mathrm{n}=458$} \\
\hline No interference; pain adequately managed & 89 & $(19.4)$ \\
\hline Little interference; pain mostly managed & 145 & $(31.7)$ \\
\hline Moderate interference; pain moderately managed & 202 & $(44.1)$ \\
\hline $\begin{array}{l}\text { Complete interference with adequate pain } \\
\text { management; pain not at all managed }\end{array}$ & 22 & $(4.8)$ \\
\hline \multicolumn{3}{|c|}{$\begin{array}{l}\text { aThis category is not mutually exclusive; participants were able to select more thar } \\
1 \text { type of chronic pain. } \\
S D=\text { standard deviation. }\end{array}$} \\
\hline
\end{tabular}

The correlations between relief of constipation (as assessed by the question "How well did <treatment> relieve your constipation?") and satisfaction with treatment (as assessed by the question "How satisfied were you with <treatment> for your constipation?") at baseline are shown in Table 2. Increasing levels of relief from constipation were associated with increasing levels of satisfaction for all treatments; correlations were moderate to high $(>-0.55)$ and statistically significant $(P<0.001)$. The correlations for the natural/behavioral therapies ranged from -0.72 to -0.74 and the correlations for OTC products ranged from -0.55 to -0.80 , with fiber supplements demonstrating the weakest correlation between relief and satisfaction, 


\begin{tabular}{|c|c|}
\hline $\begin{array}{l}\text { Correlations } \\
\text { by Natural/B } \\
\text { Laxative Age }\end{array}$ & $\begin{array}{l}\text { d Satisfaction } \\
\text { herapy and } \\
\text { ne }^{a}\end{array}$ \\
\hline Satisfaction with Treatment ${ }^{b}$ & $\begin{array}{l}\text { Relief Experience } \\
\text { with Laxativec }\end{array}$ \\
\hline Probiotics $(n=202)$ & $-0.73^{d}$ \\
\hline Natural diet change $(n=299)$ & $-0.72^{d}$ \\
\hline Increased fluids $(\mathrm{n}=350)$ & $-0.74^{d}$ \\
\hline Increased exercise $(n=130)$ & $-0.74 \mathrm{~d}$ \\
\hline OTC fiber supplements $(\mathrm{n}=88)$ & $-0.55^{d}$ \\
\hline OTC stool softeners $(n=132)$ & $-0.59^{\mathrm{d}}$ \\
\hline OTC osmotic laxatives $(n=84)$ & $-0.70^{\mathrm{d}}$ \\
\hline OTC stimulant laxatives $(\mathrm{n}=145)$ & $-0.62^{\mathrm{d}}$ \\
\hline OTC saline laxatives $(n=47)$ & $-0.80^{d}$ \\
\hline OTC rectal options $(n=35)$ & $-0.68^{d}$ \\
\hline Rx osmotic laxatives $(n=47)$ & $-0.67^{\mathrm{d}}$ \\
\hline Rx lactulose $(n=39)$ & $-0.74^{d}$ \\
\hline Rx Amitiza $(\mathrm{n}=9)$ & $-0.95^{\mathrm{d}}$ \\
\hline Rx Relistor $(\mathrm{n}=2)$ & -1.00 \\
\hline \multicolumn{2}{|c|}{$\begin{array}{l}\text { aSpearman's correlations are inversely related due to response patterns, as shown } \\
\text { in item wordino }\end{array}$} \\
\hline \multicolumn{2}{|c|}{$\begin{array}{l}\text { b"How satisfied were you with <treatment> for your constipation? Very satisfied, } \\
\text { somewhat satisfied, somewhat dissatisfied, very dissatisfied." }\end{array}$} \\
\hline \multicolumn{2}{|c|}{$\begin{array}{l}\text { "How well did <treatment }>\text { relieve your constipation? No relief, slight relief, } \\
\text { moderate relief, complete relief." } \\
d P<0.001 \text {. }\end{array}$} \\
\hline \multicolumn{2}{|l|}{ OTC $=$ over-the-counter $; R x=$ prescription . } \\
\hline
\end{tabular}

and saline laxatives demonstrating the strongest correlation. The correlations for prescription options ranged from -0.67 to -1.00. At week 24, increasing levels of relief continued to be associated with increasing levels of satisfaction for all agents (data not shown).

Although the overall association between symptom relief and satisfaction was strong for all therapies, a closer look at the relationship reveals differences and discrepancies in the connection between relief and satisfaction in the various laxative therapies. Almost three quarters $(n=65 ; 72 \%)$ of the 90 patients who took OTC osmotic laxatives in the 2 weeks prior to baseline reported that they were somewhat or very satisfied with the therapy, leaving 25 (28\%) patients somewhat or very dissatisfied with how well OTC osmotic laxatives relieved their constipation. However, almost half $(47 \%)$ of these patients experienced at best only slight relief from the therapy.

Similarly, among the 146 patients who had used OTC stimulant laxatives in the 2 weeks prior to baseline, 73\% ( $\mathrm{n}=106)$ reported being at least somewhat satisfied with the therapy, leaving $27 \%$ dissatisfied; yet still $37 \%$ received no or only slight relief. More than half (58\%) of patients who used OTC fiber supplements reported being satisfied with the treatment, yet only $38 \%$ of those patients received moderate or complete relief. Two thirds (68\%) of patients who used OTC stool softeners were satisfied with the treatment; only slightly more than half $(52 \%)$ of these patients received moderate or complete relief from the OTC stool softeners. Similar results were observed with OTC saline laxatives and OTC rectal options.

Among the 39 patients who had used prescription lactulose in the 2 weeks prior to baseline, three quarters $(n=30 ; 77 \%)$ reported being at least somewhat satisfied with the therapy and half (44\%) of these patients indicated that they received at best only slight relief from lactulose. Thirty-nine (81\%) of the 48 patients who used prescription osmotic laxatives (polyethylene glycol, 3,350) reported being at least somewhat satisfied and $73 \%$ reported moderate or complete relief. These results were relatively consistent across the 24-week follow-up.

The most common cause of dissatisfaction with laxative therapy was lack of efficacy ("Did not relieve constipation"; Table 3). More than half of the patients who used OTC laxatives and were dissatisfied with the treatment reported that the lack of relief was a cause for this dissatisfaction (range: 58\% for stimulant laxatives to $84 \%$ for osmotic laxatives). Although the sample sizes were smaller for prescription laxatives, the trend was the same.

The BSW satisfaction responses were divided between patients who took only OTC medications and those who took only prescription medications at each survey time point (Table 4). At baseline, $72 \%$ of the 268 OTC users and $70 \%$ of the 46 prescription laxative users responded that they had received benefit from their constipation treatment. A total of $41 \%$ of the OTC users responded that they were satisfied with their constipation treatment, while $61 \%$ of the prescription laxative users were satisfied. Almost all of the patients (96\% of OTC users and $100 \%$ of prescription laxative users) indicated that they would be willing to continue this constipation treatment. At week 24, $77 \%$ of the OTC users had received benefit from their constipation treatment. Slightly more than half (55\%) of the OTC users were satisfied with the treatment, yet $93 \%$ were willing to continue the OTC therapy. A total of $84 \%$ of the prescription users received benefit, $78 \%$ were satisfied, and all indicated that they would be willing to continue the prescription therapy

Despite using natural/behavioral therapies and/or laxatives for their OIC, patients still found it necessary to also adjust their pain medication in order to have a BM. At baseline (and similarly throughout follow-up), $8 \%$ of patients indicated that they changed how they used their opioid pain medicines in the past 7 days so that they could have a BM. Almost half (43\%) decreased the dose or frequency ("Reduced how much of my pain medication I use") and 49\% temporarily stopped their opioid medication. Despite these changes in the opioid medication regimen, $65 \%$ were not satisfied with how such change relieved their constipation. With the change in opioid use, $78 \%$ indicated that their pain was at least a little worse (49\% reported "much worse" pain) after the medication adjustment. 
TABLE 3 Reasons for Dissatisfaction with Laxatives at Baseline by Laxative Classification

\begin{tabular}{|c|c|c|c|c|c|c|c|c|c|c|}
\hline \multirow[b]{2}{*}{$\begin{array}{l}\text { Reason Dissatisfied, } \\
\text { n (\%) }\end{array}$} & \multicolumn{6}{|c|}{ OTC } & \multicolumn{4}{|c|}{ Prescription } \\
\hline & $\begin{array}{c}\text { Fiber } \\
\text { Supplements } \\
\mathbf{n}=37\end{array}$ & $\begin{array}{l}\text { Stool } \\
\text { Softeners } \\
\mathbf{n}=43\end{array}$ & $\begin{array}{c}\text { Osmotic } \\
\text { Laxatives } \\
\mathbf{n}=25\end{array}$ & $\begin{array}{c}\text { Stimulant } \\
\text { Laxatives } \\
\mathbf{n}=40\end{array}$ & $\begin{array}{c}\text { Saline } \\
\text { Laxatives } \\
\mathbf{n}=23\end{array}$ & $\begin{array}{l}\text { Rectal } \\
\text { Options } \\
\mathbf{n}=10\end{array}$ & $\begin{array}{l}\text { Osmotic } \\
\text { Laxatives } \\
\mathbf{n}=9\end{array}$ & $\begin{array}{c}\text { Lactulose } \\
\mathbf{n}=9\end{array}$ & $\begin{array}{c}\text { Amitiza } \\
\mathbf{n}=7\end{array}$ & $\begin{array}{c}\text { Relistor } \\
n=1\end{array}$ \\
\hline $\begin{array}{l}\text { Did not relieve } \\
\text { constipation }\end{array}$ & $26 \quad(70.3)$ & $31 \quad(72.1)$ & $21 \quad(84.0)$ & $23(57.5)$ & $15 \quad(65.2)$ & $\begin{array}{ll}6 \quad(60.0) \\
\end{array}$ & $\begin{array}{ll}3 & (33.3)\end{array}$ & $6(66.7)$ & $5(71.4)$ & $1(100.0)$ \\
\hline Stools too loose & $5 \quad(13.5)$ & $6(14.0)$ & $4(16.0)$ & $4(10.0)$ & $3(13.0)$ & $\begin{array}{ll}0 & (0.0)\end{array}$ & $2(22.2)$ & 1 (11.1) & $0 \quad(0.0)$ & $(0.0)$ \\
\hline $\begin{array}{l}\text { Feeling of needing to } \\
\text { have a BM comes on } \\
\text { too quickly }\end{array}$ & $4 \quad(10.8)$ & $4 \quad(9.3)$ & $1 \quad(4.0)$ & $5(12.5)$ & $3 \quad(13.0)$ & $\begin{array}{ll}0 & (0.0)\end{array}$ & $1 \quad(11.1)$ & $3(33.3)$ & $0 \quad(0.0)$ & $(0.0)$ \\
\hline $\begin{array}{l}\text { Could not tolerate side } \\
\text { effects of treatment }\end{array}$ & $4 \quad(10.8)$ & 5 (11.6) & $3(12.0)$ & $7(17.5)$ & $2 \quad(8.7)$ & $1 \quad(10.0)$ & $2(22.2)$ & 1 (11.1) & $3(42.9)$ & $1(100.0)$ \\
\hline Inconvenient to use & $5 \quad(13.5)$ & $3 \quad(7.0)$ & $3(12.0)$ & $3 \quad(7.5)$ & $2 \quad(8.7)$ & $2(20.0)$ & $2(22.2)$ & $2(22.2)$ & $0 \quad(0.0)$ & $(0.0)$ \\
\hline $\begin{array}{l}\text { Unpleasant to take } \\
\text { or use }\end{array}$ & $\begin{array}{ll}6 & (16.2)\end{array}$ & $3 \quad(7.0)$ & $4(16.0)$ & $4(10.0)$ & $7 \quad(30.4)$ & $3(30.0)$ & $2 \quad(22.2)$ & $6(66.7)$ & $1(14.3)$ & $(0.0)$ \\
\hline Expensive & $4 \quad(10.8)$ & $5(11.6)$ & $2 \quad(8.0)$ & $6(15.0)$ & $3(13.0)$ & $1 \quad(10.0)$ & $2(22.2)$ & $1(11.1)$ & $2(28.6)$ & $(0.0)$ \\
\hline Other & $2 \quad(5.4)$ & $6(14.0)$ & $1 \quad(4.0)$ & $7(17.5)$ & $(8.7)$ & $2(20.0)$ & $1 \quad(11.1)$ & 1 (11.1) & $1(14.3)$ & $(0.0)$ \\
\hline
\end{tabular}

\section{Physician-Reported Treatment Recommendations and Knowledge of Patient's Constipation}

Physicians reported that only $14 \%$ of their patients were completely satisfied with laxative use. Similarly, less than $10 \%$ of physicians felt that all available treatments were "completely adequate" in relieving OIC. Instead, physicians commonly recommended decreasing the daily opioid dose (21\%) or frequency of opioid use (18\%) or taking an opioid holiday (17\%). The proportion of agreement between participant and physician reports of presence of constipation at baseline was $65 \%$, meaning that $35 \%$ of the physicians did not know that their patients were experiencing constipation. Further, the proportion of agreement between participant and physician reports of laxative use at baseline was 57\%; 17\% of physicians indicated that their patients were not taking laxatives, when in fact they were; and $26 \%$ of physicians indicated that they did not know their patients' laxative status.

\section{Discussion}

These analyses were conducted to generate real-world empirical evidence to better understand the ways in which patients with chronic noncancer pain and OIC try to address their constipation symptoms and the effectiveness of and satisfaction with these constipation treatments. Overall, correlations between relief of constipation and satisfaction with treatment were moderate to high, indicating that in general, increasing levels of relief from constipation were associated with increasing levels of satisfaction. However, high proportions of patients in this study received no relief at all or only slight relief with each of the therapies, yet were still satisfied and willing to continue with the therapy. In light of available therapies, when patients and their prescribers did have a discussion about OIC, the most common recommendation by prescribers was to take an opioid holiday.
These results are consistent with the theory of reasoned action (TRA). ${ }^{18-20}$ The TRA was developed to understand the relationship between attitudes and behaviors. Shikiar and Rentz (2004) $)^{12}$ proposed applying the TRA to understand satisfaction with medication, with satisfaction considered to be the attitude toward the medication. As Fishbein and Ajzen (1975) proposed, a patient's attitude is determined by the patient's beliefs about the outcomes of performing the behavior, in conjunction with his/her evaluation of the outcomes. ${ }^{20}$ When this theory is applied to medication, a positive attitude toward medication is achieved when a patient believes that positive results (e.g., high efficacy such as a decrease in symptoms, no adverse effects, little to no impact on his/her ability to carry on with daily life) will result from taking the medication as prescribed. Conversely, if a patient believes that the medication will produce more negative outcomes (e.g., low efficacy, strong or multiple adverse effects, negative impact on activities of daily living, negative impact on health-related quality of life [HRQOL]), that patient will have a less positive attitude toward the medication. These attitudes are formed prior to any actual usage of the medication.

It is possible that patients with OIC have positive attitudes toward natural/behavioral therapies because of the ease of implementation (drink more water, eat some yogurt, eat more fiber), low chance of adverse effects, and low barriers to ongoing use. Their expectations for the therapy are positive; therefore, they are willing to continue with the therapy, regardless of the level of symptom relief and satisfaction with treatment achieved. Conversely, patients with OIC likely have higher expectations of prescription laxatives due to the barriers of obtaining the medication (doctor's office visit, pharmacy visit, copay) and the potential side effects (abdominal cramping, 
TABLE 4 Benefit, Satisfaction, and Willingness to Continue Treatment: Over-the-Counter Versus Prescription Laxative Users

\begin{tabular}{|c|c|c|c|c|c|c|c|c|}
\hline & \multicolumn{4}{|c|}{ Baseline } & \multicolumn{4}{|c|}{ Week 24b } \\
\hline & \multicolumn{2}{|c|}{ OTC Therapies } & \multicolumn{2}{|c|}{ Prescription Laxatives } & \multicolumn{2}{|c|}{ OTC Therapies } & \multicolumn{2}{|c|}{ Prescription Laxatives } \\
\hline Baseline $^{\mathrm{a}}$ & \multicolumn{2}{|c|}{$\mathrm{n}=268$} & \multicolumn{2}{|c|}{$\mathrm{n}=46$} & \multicolumn{2}{|c|}{$\mathrm{n}=171$} & \multicolumn{2}{|c|}{$\mathbf{n}=37$} \\
\hline \multicolumn{9}{|c|}{ Have you had any benefit from your constipation treatment? n (\%) } \\
\hline No & 76 & $(28.4)$ & 14 & (30.4) & 39 & $(22.8)$ & 6 & $(16.2)$ \\
\hline Yes & 192 & $(71.6)$ & 32 & $(69.6)$ & 132 & $(77.2)$ & 31 & $(83.8)$ \\
\hline \multicolumn{9}{|l|}{ If yes, how much benefit? $n(\%)$} \\
\hline Little benefit & 113 & $(58.9)$ & 8 & $(25.0)$ & 82 & $(62.1)$ & 11 & $(35.5)$ \\
\hline Much benefit & 79 & $(41.1)$ & 24 & $(75.0)$ & 49 & $(37.1)$ & 20 & $(64.5)$ \\
\hline Missing & 0 & $(0.0)$ & 0 & $(0.0)$ & 1 & $(0.8)$ & 0 & $(0.0)$ \\
\hline $\begin{array}{l}\text { Taking all things into account, are you satisfied } \\
\text { with your constipation treatment? } \mathrm{n}(\%)^{\mathrm{c}}\end{array}$ & \multicolumn{2}{|c|}{$\mathrm{n}=169$} & \multicolumn{2}{|c|}{$n=43$} & \multicolumn{2}{|c|}{$\mathrm{n}=171$} & \multicolumn{2}{|c|}{$\mathrm{n}=37$} \\
\hline No & 100 & $(59.2)$ & 17 & $(39.5)$ & 77 & $(45.0)$ & 8 & $(21.6)$ \\
\hline \multicolumn{9}{|l|}{ If no, how dissatisfied? $n(\%)$} \\
\hline A little dissatisfied & 51 & $(51.0)$ & 11 & $(64.7)$ & 50 & $(64.9)$ & 6 & $(75.0)$ \\
\hline Very dissatisfied & 49 & $(49.0)$ & 6 & $(35.3)$ & 27 & $(35.1)$ & 1 & $(12.5)$ \\
\hline Missing & 0 & $(0.0)$ & 0 & $(0.0)$ & 0 & $(0.0)$ & 1 & $(12.5)$ \\
\hline Yes & 69 & $(40.8)$ & 26 & $(60.5)$ & 94 & $(55.0)$ & 29 & $(78.4)$ \\
\hline \multicolumn{9}{|l|}{ If yes, how satisfied? n (\%) } \\
\hline A little satisfied & 35 & $(50.7)$ & 9 & $(34.6)$ & 54 & $(57.4)$ & 11 & $(37.9)$ \\
\hline Very satisfied & 34 & $(49.3)$ & 17 & $(65.4)$ & 40 & $(42.6)$ & 18 & $(62.1)$ \\
\hline \multicolumn{9}{|c|}{ Would you be willing to continue constipation treatment with this medication? n (\%) } \\
\hline No & 12 & $(4.5)$ & 0 & $(0.0)$ & 12 & $(7.0)$ & 0 & $(0.0)$ \\
\hline \multicolumn{9}{|l|}{ If no, how unwilling? $n(\%)$} \\
\hline A little unwilling & 10 & $(83.3)$ & 0 & $(0.0)$ & 11 & $(91.7)$ & 0 & $(0.0)$ \\
\hline Very unwilling & 2 & $(16.7)$ & 0 & $(0.0)$ & 1 & $(8.3)$ & 0 & $(0.0)$ \\
\hline Yes & 256 & $(95.5)$ & 46 & $(100.0)$ & 159 & $(93.0)$ & 37 & $(100.0)$ \\
\hline \multicolumn{9}{|l|}{ If yes, how willing? $n(\%)$} \\
\hline A little bit willing & 76 & $(29.7)$ & 4 & $(8.7)$ & 67 & $(42.1)$ & 3 & $(8.1)$ \\
\hline Very willing & 179 & $(69.9)$ & 42 & $(91.3)$ & 92 & $(57.9)$ & 34 & (91.9) \\
\hline Missing & 1 & $(0.4)$ & 0 & $(0.0)$ & 0 & $(0.0)$ & 0 & $(0.0)$ \\
\hline \multicolumn{9}{|c|}{$\begin{array}{l}\text { aThe } n \text { presented in each column presents the total number of patients completing the questionnaire. The exact denominator for fre } \\
\text { cases where item-level data are missing. } \\
{ }^{2} \text { The results at week } 12 \text { are similar to the results at week } 24 \text {. } \\
\text { cDue to a problem with the programming of the survey, this question was not presented to } 29 \text { participants. The data are missing. } \\
\text { OTC = over-the-counter. }\end{array}$} \\
\hline
\end{tabular}

diarrhea) from the medications. Further research is needed to examine patients' attitudes, expectations, satisfaction, and willingness to continue the various OIC therapies in light of each therapy's effectiveness.

Setting patients' expectations for therapy is important since their expectations are a significant mediator of their satisfaction with therapy. Although many factors influence patients' expectations about a medication, clinicians have the opportunity to educate patients and speak with them about their therapy to help set realistic expectations. Satisfaction with therapy is a multifaceted concept, influenced by factors such as attitudes toward the medication; expectations for the medication; experience while on the medication; information, support, and encouragement from the patient's clinician; and even the patient's personality. OIC is a burdensome condition, caus- ing significant symptoms and negatively affecting a patient's HRQOL. Because of this, a patient may be willing to tolerate lower efficacy than desired because any improvement is better than nothing. However, low efficacy should not be accepted, since complete relief of OIC symptoms may help facilitate better pain management.

It is vitally important for clinicians to initiate discussions about OIC during patients' clinical visits and probe on patients' experiences. Although correlations between relief of constipation and satisfaction with treatment were strong, clinicians should inquire about effectiveness rather than satisfaction when assessing treatment options, as patients reported being satisfied with treatment despite minimal effectiveness. A patient's reply about his/her constipation therapy could be different, depending on if the clinician asks about 
effectiveness, satisfaction with symptom relief, willingness to continue with the treatment, or expectations for therapy. The symptom burden of OIC is significant, bothersome, and persistent. ${ }^{10,21}$ Despite using laxatives, patients do not reach their desired number of BMs per week, and OIC-related symptoms are severe, such as straining/squeezing to pass a BM; too hard, incomplete, and painful BMs; and flatulence, bloating, and abdominal discomfort. Each of these issues contributes to the patient's experience and needs to be included in the clinicianpatient discussion to optimize OIC management. In addition, as the most common recommendation for OIC recorded in this study was to take an opioid holiday, better clinician education is needed about treatment options for OIC.

\section{Limitations}

The authors acknowledge the limitations of this study. First, data for these analyses were obtained via a web survey, which is subject to response bias and access bias. It is possible that patients in this study were more tech-savvy than the overall OIC patient population and may have had more exposure to online direct-to-consumer advertising and access to information regarding treating OIC on the internet, which could influence their expectations for the therapy and therefore influence their ratings of satisfaction with the therapy. Second, the survey did not include questions on the patients' attitudes toward any of the medications. The items on satisfaction with the constipation therapies were interpreted by each patient individually, without reference to previous expectations for the therapy. Lastly, only $60 \%$ of the sample completed 7 of the 8 follow-up visits. While there were no differences in the demographics of completers versus non-completers, this attrition could bias these results. Despite these limitations, the authors feel that this study provides an increased understanding of the satisfaction and perceived relief or benefit of constipation therapies among adults with OIC.

\section{Conclusions}

While increased relief from OIC was associated with increased satisfaction for all therapies, there remains a substantial number of patients who report satisfaction despite having inadequate relief from OIC that merits further investigation. Importantly, satisfaction is a multidimensional construct, influenced by a patient's expectation for the therapy, experience with the therapy, and effectiveness. Addressing OIC may help to improve pain management and pain control and overall satisfaction, and this can be aided by specific and informed discussions between the provider and the patient. Patients have opinions and experiences to share with their providers to obtain advice and strive toward the highest-quality outcomes. Clinicians can be better informed to advise and provide guidance to patients about evolving treatment options for OIC.

\section{Authors}

ROBERT J. LOCASALE, PhD, MS, is Director, Quality, Design $\mathcal{E}$ Analytics, Medical Evidence and Observational Research, and CATHERINE DATTO, MD, MS, is U.S. Medical Affairs Medical Lead, AstraZeneca Pharmaceuticals, Wilmington, Delaware. MARY KAY MARGOLIS, MHA, MPH, is Senior Program Officer, Science, Patient-Centered Outcomes Research Institute (PCORI), Washington, DC, and KARIN S. COYNE, PhD, MPH, is Vice President, Research, Evidera, Bethesda, Maryland.

AUTHOR CORRESPONDENCE: Robert J. LoCasale, PhD, MS, Director, Quality, Design \& Analytics, Medical Evidence and Observational Research, AstraZeneca Pharmaceuticals, 1800 Concord Pike, P.O. Box 15437, Wilmington, DE 19850-5437. Tel.: 301.398.0295; E-mail: robert.locasale@astrazeneca.com.

\section{DISCLOSURES}

This study and the writing of the manuscript were funded in full by AstraZeneca. Coyne is an employee of Evidera and was a scientific consultant to AstraZeneca in connection with this study and development of this manuscript. Margolis was employed by Evidera at the time this study was conducted and the manuscript completed. LoCasale and Datto are employees of AstraZeneca. All authors reviewed and approved the final manuscript.

Study design was contributed by LoCasale, Datto, and Coyne. Coyne took the lead in data collection, and all authors were involved in data interpretation. The manuscript was written and revised by all authors

\section{ACKNOWLEDGMENTS}

The authors would like to acknowledge the work of the following employees of AstraZeneca who contributed to the study design and implementation: Fred King, Soheil Chavoshi, and Ron Dirienzi. The authors would also like to acknowledge the work of Christine Thompson at Evidera, who contributed to the data analysis and interpretation. Lastly, Colleen Valenzuela and Jersino Jean-Mary at UnitedBioSource Corporation contributed to the study implementation and data collection.

\section{REFERENCES}

1. Kumar L, Barker C, Emmanuel A. Opioid-induced constipation: pathophysiology, clinical consequences, and management. Gastroenterol Res Pract. 2014;2014:141737.

2. Cook SF, Lanza L, Zhou X, et al. Gastrointestinal side effects in chronic opioid users: results from a population-based survey. Aliment Pharmacol Ther. 2008;27(12):1224-32

3. Panchal SJ, Muller-Schwefe P, Wurzelmann JI. Opioid-induced bowel dysfunction: prevalence, pathophysiology and burden. Int J Clin Pract. 2007;61(7):1181-87

4. Penning-van Beest FJ, van den Haak P, Klok RM, et al. Quality of life in relation to constipation among opioid users. J Med Econ. 2010;13(1):129-35.

5. Rosti G, Gatti A, Costantini A, et al. Opioid-related bowel dysfunction: prevalence and identification of predictive factors in a large sample of Italian patients on chronic treatment. Eur Rev Med Pharmacol Sci. 2010;14(12):1045-50.

6. Bell TJ, Panchal SJ, Miaskowski C, et al. The prevalence, severity, and impact of opioid-induced bowel dysfunction: results of a U.S. and European Patient Survey (PROBE 1). Pain Med. 2009;10(1):35-42. 
7. Coyne KS, LoCasale RJ, Datto CJ, et al. Opioid-induced constipation in patients with chronic noncancer pain in the USA, Canada, Germany, and the UK: descriptive analysis of baseline patient-reported outcomes and retrospective chart review. Clinicoecon Outcomes Res. 2014a;6:269-81.

8. Hjalte F, Berggren AC, Bergendahl H, et al. The direct and indirect costs of opioid-induced constipation. J Pain Symptom Manage. 2010;40(5):696-703.

9. Manchikanti L, Abdi S, Atluri S, et al. American Society of Interventional Pain Physicians (ASIPP) guidelines for responsible opioid prescribing in chronic non-cancer pain: part 2--guidance. Pain Physician. 2012;15(3 Suppl):S67-16.

10. Coyne KS, Margolis MK, Yeomans K, et al. Opioid-induced constipation among patients with chronic noncancer pain in the United States, Canada, Germany, and the United Kingdom: laxative use, response, and symptom burden over time. Pain Med. 2015;16(8):1551-65.

11. Aharony L, Strasser S. Patient satisfaction: what we know about and what we still need to explore. Med Care Rev. 1993;50(1):49-79.

12. Shikiar R, Rentz AM. Satisfaction with medication: an overview of conceptual, methodologic, and regulatory issues. Value Health. 2004;7(2):204-15.

13. Barbosa CD, Balp M-M, Kulich K, et al. A literature review to explore the link between treatment satisfaction and adherence, compliance, and persistence. Patient Prefer Adherence. 2012;6:39-48.
14. Kaufmann J, Feist E, Roske AE, et al. Monotherapy with tocilizumab or TNF-alpha inhibitors in patients with rheumatoid arthritis: efficacy, treatment satisfaction, and persistence in routine clinical practice. Clin Rheumatol. 2013;32(9):1347-55.

15. Carr AJ, Thompson PW, Cooper C. Factors associated with adherence and persistence to bisphosphonate therapy in osteoporosis: a cross-sectional survey. Osteoporos Int. 2006;17(11):1638-44

16. Mydlo JH, Volpe MA, MacChia RJ. Results from different patient populations using combined therapy with alprostadil and sildenafil: predictors of satisfaction. BJU Int. 2000;86(4):469-73.

17. Pleil AM, Coyne KS, Reese PR, et al. The validation of patient-rated global assessments of treatment benefit, satisfaction, and willingness to continue--the BSW. Value Health. 2005;8 Suppl 1:S25-34.

18. Ajzen I, Heilbroner RL, Fishbein M, Thurow LC. Understanding Attitudes and Predicting Social Behaviour. Englewood Cliffs, NJ: Prentice Hall PTR; 1980.

19. Fishbein M. Attitude and the prediction of behavior. In: Fishbein M, ed. Readings in Attitude Theory and Measurement. New York: Wiley; 1967:477-92.

20. Fishbein M, Ajzen I. Belief, Attitude, Intention, and Behavior: An Introduction to Theory and Research. Reading, MA: Addison-Wesley; 1975.

21. Coyne KS, Currie BM, Holmes WC, et al. Assessment of a stool symptom screener and understanding the opioid-induced constipation symptom experience. Patient. 2014b:1-11. 